\title{
Experimental Comparison Analysis of White Coated and Black Coated Inside Box Type Solar Cooker
}

\author{
Agernew Melkamu Bayabl ${ }^{1}$ and A.Balasuadhakar ${ }^{2}$ \\ ${ }^{1,2}$ School of Mechanical and Industrial Engineering \\ Dire Dawa Institute of Technology \\ Dire Dawa University, Ethiopia
}

\begin{abstract}
The need to cook food for sustenance is fundamental to nearly every society and requires the expenditure of energy in some form. Solar energy can be harnessed to meet this need without the environmental and health problems associated with most other fuels. There are a wide variety of devices designed to capture the sun's energy and harness it for cooking food. The aim of this paper is to report comparisons and analysis made between box type solar cookers with the same dimension, shape and size by differentiating coated inside white and black coated. The experiment takes place at morning 10:30-12:50 (Ethiopian local time). It uses standard water boiling test. Water with the same volume put inside the black pot and compare which box boils the water quicker. From the experiment, the maximum water temperature recorded $75.63^{\circ} \mathrm{C}$ from white coated and $68.62^{\circ} \mathrm{C}$ from black coated at the same time. Input energy is the same for both solar cookers based on this maximum useful energy for boiling the water recorded at 4:50 pm, the result Eout white coated $6501.26 \mathrm{~J}$ and Eout black coated $5660.87 \mathrm{~J}$. Finally the test results indicate the white-coated reflect the input solar energy without absorbing to the black pot this brings white coated solar box is efficient as compare with black coated.
\end{abstract}

KeyWords: Box Solar Cookers, Maximum Temperature, Useful Energy.

\section{INTRODUCTION}

Solar cooking is one of the cheapest alternatives in countries where there is plenty of sunshine. There are various kinds of solar cooker technologies. One of the simplest technologies is the box solar cooker Box solar cookers can be used to cook variety of food items. However, box solar cookers have their own limitation. It is not possible to cook food items which need high temperature. Hence, the cookers cannot completely replace other energy sources. It can reduce the dependence on unsustainable use of biomass or any other non-renewable sources. The other limitation is that box solar cookers need sometime which may range 2-3 hours to cook food. Compared to electric or biomass stoves, the cooking time is long. This limitation is probably the most influencing factor for users to accept solar cooking. Increasing environmental awareness and the growing global need for alternative cooking fuels has spurred solar cooker research and development. Solar cookers represent a simple, low cost, practical and effective application of solar energy. In many developing countries, such as Ethiopia, they can play an important role in improving living conditions among low-income households by lowering exposure to wood-smoke and reducing pressure on firewood resources. It is unlikely that they will substitute for conventional gas or electric cooking in developed countries; however their use could improve safety and protect the environment. Different types of solar cookers have been developed and tested over the world. There has been a considerable interests recently in the design, development and testing of various types of solar cookers. The procedures followed to evaluate the performance of solar cookers consist of determining one of the following: (i) cooking time for different food products, (ii) the time required for a sensible heating of a known quantity of water up to the boiling point or (iii) the stagnation plate temperature recorded in a test without load. The second and the third methods are better approaches. Standard test procedure for box-type solar cookers Proposed. The purpose of this project is to compare the efficiency of two box type solar cookers. They have the same dimension, shape and size but different color coated inside. One is black and the other white coated inside.

\section{LITERATURE REVIEW}

Solar Cookers may vary from type to type but they all use the same basic principles. First the food is prepared and the ingre dients required cooking a particular meal assembled and then placed in the cooking container which maybe a pot or pan. The container is then placed inside the solar cooker which is the placed in direct sunlight. If the solar cooker is entirely placed in direct sunlight, then the shadow of the cooker will not overlap with the shadow of any nearby object. The cooker is then turned towards the direction of the sun and left until the food is cooked. The oven must be checked every one or two hours in order to turn the stove towards the direction of the sun. The time required to cook the meal varies from cooker to cooker and it primarily depends on the 
equipment being used, the amount of sunlight at that particular time and the quantity of food that is being prepared. Air temperature, wind and latitude also affect the performance of the device (Khalifa, M, \& M, 1985).

The solar box cooker consists, largely some type of heat trapping enclosure. Quite often, this takes the form of a box made of insulating material with one face of the box fitted with a transparent medium, such as glass or transparent plastic. This allows the box to take advantage of the greenhouse effect and incident solar radiation cooks the food within the box. The ability of solar cookers to collect sunlight is directly related to the projected area of the collector perpendicular to the incident radiation. For example, a large box with a glass lid will function as a solar box cooker but the losses due to heat loss over a larger surface area will, at least partially, offset the gain of having a large collector surface. Instead, what is typically done is to create an insulated box with a glazed surface cover and use reflectors to increase the apparent collector area. These reflectors can be made from variety of materials and their primary purpose is to reflect sunlight through the glazing material and into the cooking space inside of the box (Ademola and Rahman, 2013). Hot solar box cookers are simple in terms of fabrication, handling, operation, cheap and effective with minimal attendance required during the cooking process (Hussein et al., 2008; Muthusivagami et al., 2010).

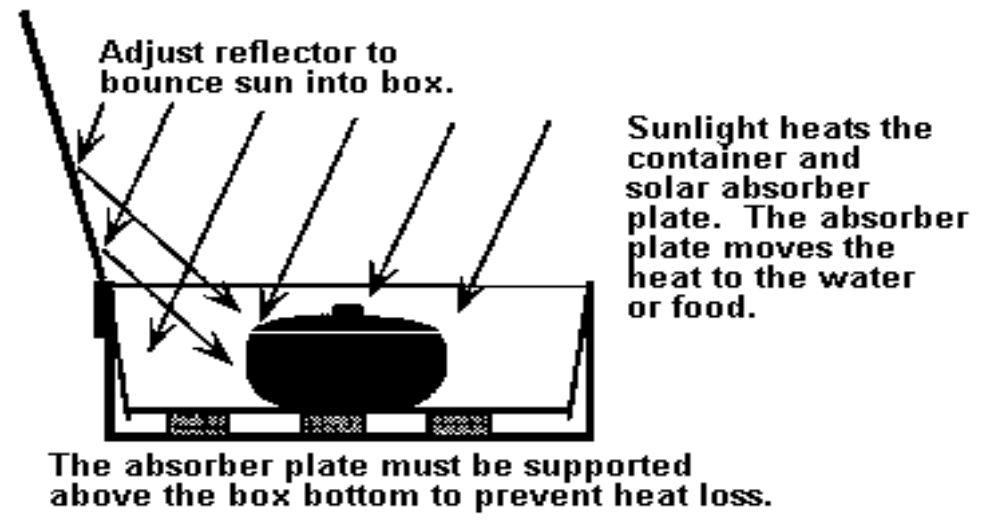

Figure 1: Is a schematic of the operating simple solar box cooker. Image courtesy of Solar Cooking Archives.

From thermodynamic point of view the function of a solar box cooker is to trap and contain the heat of the sun inside it and to transfer the heat to the cooking pot as efficiently as possible. The heat retained inside the insulated box with a transparent cover is based on the greenhouse effect. The light energy (which is short wave energy) that enters the cooker through the transparent top cover is absorbed by the black pots and the black bottom metal plate. The shortwave light energy is then converted into long wavelength heat energy and radiated from the interior materials. Most of this radiant heat energy is trapped inside the cooker and can (mostly) not radiated back out because of its longer wavelength. Although the transparent cover traps most of the radiant heat, some does escape directly through the lid (Dincer and Cengel, 2001).

\section{MATERIAL AND METHODOLOGY}

Comparison of the two box type solar cookers with the same dimension, shape and size but one coated with white inside and the other coated with black inside performance and to select the best one. Solar box cookers were identified for the experiment. The solar radiation was recorded by a pynorometer. The overall structure of Box solar cooker black coated inside (b) and white coated inside (w) with black pot are shown on Figure 12 and Figure 2.The instruments used in this project are listed on Table 1. The laptop used to integrate with the data acquisition system through software called lab view and display the data. Data acquisition system senses measured, converts analog to digital. Pyrometer measures the solar radiation in the environment and displays it.

Table 1 Description of Material

\begin{tabular}{|c|c|c|l|l|}
\hline No & Name & Quantity & \multicolumn{2}{|c|}{ Description } \\
\hline 1 & Data acquisition & 1 & $\begin{array}{l}\text { Made in hangar, } \\
\text { Module:cdaq9172 } \\
\text { Part No. 191575f/01 } \\
\text { Serial No. 1493f/88 }\end{array}$ & $\begin{array}{l}\text { Data acquisition includes sensing, analog to digital } \\
\text { converter, recording and displaying of measured }\end{array}$ \\
\hline 2 & Pyrometer & 1 & $\begin{array}{l}\text { Module:23gf } \\
\text { Sensor: Splipe } \\
\text { Type :060501 } \\
\text { Met eon irradiance meter }\end{array}$ & $\begin{array}{l}\text { Measures solar radiation in } w / \mathrm{m}^{2} \\
\text { Uncertainty }<0.1 \% \text { of full scale }\end{array}$ \\
\hline 3 & Flask & 1 & Up to 1000ml & Measures volume of water \\
\hline 4 & Thermocouple & 2 & $\begin{array}{l}\text { K type sensor } \\
\text { Uncertainty }+1.1^{\circ} \mathrm{c}\end{array}$ & $\begin{array}{l}\text { Sensing measured(temperature) and output potential } \\
\text { difference or voltage }\end{array}$ \\
\hline 5 & Solar box 1 & 1 & Black inside & To heat water \\
\hline 6 & Solar box2 & 1 & White inside & To heat water \\
\hline 7 & Black Pot & 2 & $\ldots \ldots$ & To store water \\
\hline 8 & Laptop & 1 & $\ldots \ldots$ & $\begin{array}{l}\text { With lab view software } \\
\text { data(temperature) }\end{array}$ \\
\hline 9 & Thermometer & 1 & $\ldots \ldots$ & For calibration of thermocouple as reference \\
\hline
\end{tabular}




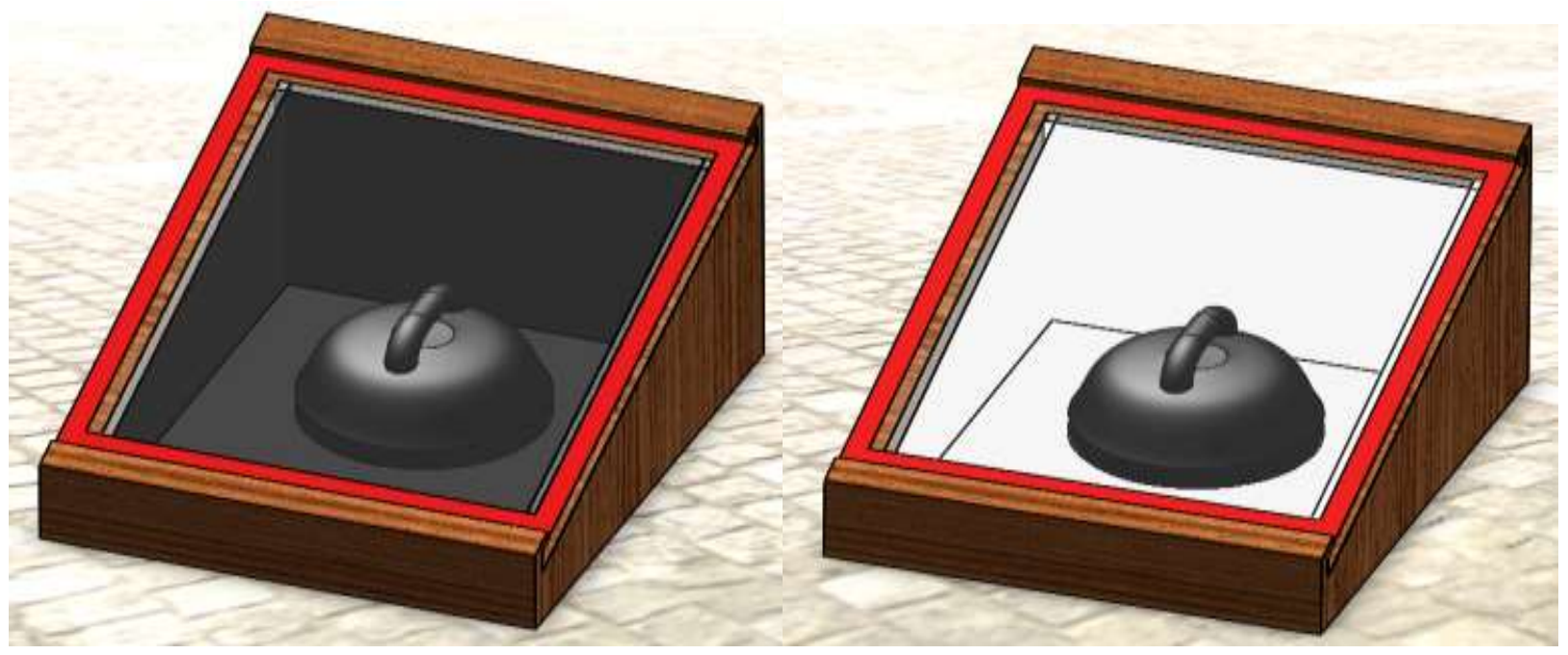

Figure 1 Solar Cooker of Black Coated (B)

Figure 2 Solar Cooker of White Coated Inside (W)

Apparatuses required in this experiment are laptop, two thermocouples, data acquisition, two cookers and pyranometer. In test, the cooking black pot was filled with 500 grams of water. Tests were conducted in accordance with the International Standard for Testing It uses standard test called water boiling test (WBT) Solar Cookers and Reporting Performance. Testing was conducted between 4:30 Pm-6:50 Pm solar times. Ambient temperature was recorded using multi-meter and ambient thermocouples Like in the calibration laptop, thermocouple and data acquisition are connected to each other. Now using a glass scaled in $\mathrm{ml}, 500 \mathrm{ml}$ water is measured and poured into each black pot. The two solar cookers with the same dimension shape and size but different coating inside and pyranometer were prepared. The two thermocouples attached to the two black pots through a hole by plaster. The thermocouple should touch the water. Finally the two pots put inside the two solar cookers each and the glass of the solar cooker should be toward the sun. A pyranometer measures solar radiation in $\left(\mathrm{w} / \mathrm{m}^{2}\right)$ and it was registered by the experimenter every 5 minute in this experiment. The pyranometer put at the center of the two solar cookers on the ground. In the laptop the lab view software was opened and added the ports where the two thermocouples attached. Finally selecting the thermocouple type and ordered to record the temperature. The experiment is performed from 4:30-6:50 for 2:20 hour's duration. In this time solar radiation manually registered every 5 minutes or 300 seconds from the pyranometer screen. In this range of time the temperature of water in each solar cooker is recorded in every one second in the laptop according to the setup in the lab view software and have total of 8886 data for each thermocouple. Because the solar radiation is registered every 5 minutes the temperature of each solar cooker should also with similar time duration. Average temperature of each solar cooker was calculated using Microsoft excel 2007 each 5 minute.

\section{RESULTS AND DISCUSSION}

During the experiment there is energy input to the solar cookers, but from the input energy only the useful energy is used to heat the water in the solar cookers. The rest was dissipated to the environment as waste. Therefore in this experiment input energy, useful energy and efficiency were calculated for each solar cooker.

\section{Energy Input $\left(E_{i}\right)$}

Energy input to the solar cooker can be computed with the following formula in every 5 minutes from 4:30-6:50.

$$
\text { Input power }=\mathrm{I}^{*} A_{a p}
$$

Input energy in time $(\Delta \mathrm{t}), E_{i}=\mathrm{I} * \operatorname{Aap} * \Delta \mathrm{t}$

Where, $\quad \mathrm{I}=$ measured solar radiation using pyranometer

$A_{a p}=$ Perpendicular to the solar radiation area of solar cookers

$$
\begin{gathered}
\Delta \mathrm{t}=t_{i}-t_{f}=5 \text { minutes or } 300 \mathrm{~s}, \\
t_{i}=\text { initial time, } t_{f}=\text { final time } \\
A_{a p}=0.1892 \mathrm{~m}^{2}
\end{gathered}
$$

Keeping (300seconds, $0.1892 \mathrm{~m}^{2}$ ) constant and varying radiation input energy calculated for the whole experimental value. Input energy is the same for both solar cookers.

Output Energy (Useful Energy) $\boldsymbol{E}_{\text {out }}$

Useful energy, the energy that changes the temperature of water in solar cooker in every 5 minutes from 4:30-6:50 


\section{Useful Energy $\boldsymbol{E}_{\text {out }}=\mathrm{m} * \mathrm{Cp} * \Delta \mathrm{T}$}

Where, $\mathrm{m}=$ mass of water,

$C_{p}=$ Specific heat capacity of water

$\Delta \mathrm{T}=T_{W i}-T_{W f}$

$T_{W i}=$ Initial water temperature, $T_{W f}=$ final water temperature,

Mass $(\mathrm{m})=$ density $*$ volume,

Density of water at room temperature $=1000 \mathrm{~kg} / \mathrm{m}^{3}$,

Volume of water

$$
\mathrm{V}=500 \mathrm{ml}(0.5 \mathrm{~L})=0.5 * 1 / 1000 \mathrm{~m} 3
$$

During experiment $500 \mathrm{ml}$ water taken, $1 \mathrm{~L}=1000 \mathrm{ml}, \mathrm{lm}^{3}=1000$ liter

$$
\begin{aligned}
& \mathrm{m}=1000 \mathrm{~kg} / \mathrm{m} 3 * 0.5 * 1 / 1000 \mathrm{~m} 3=0.5 \mathrm{~kg}, \\
& C_{p}=4187 \mathrm{~J} / \mathrm{kg} \mathrm{k}
\end{aligned}
$$

The outputs (useful energy) for the two solar cookers were different because of the temperature difference.

Efficiency of the Cooker

$$
\text { Instantaneous Efficiency }=E_{\text {out }} / E_{\text {in }}
$$

Where, $E_{\text {out }}=$ Useful Energy

$E_{\text {in }}=$ Energy Input

There is a negative efficiency value. That negative value is nothing but the temperature was decreasing during the experiment time. This is because there was cloud while the experiment is performed

\section{Assumptions and Constants}

Density of water (at room temperature) $=1000 \mathrm{~kg} / \mathrm{m}^{3}$, specific heat capacity of water

$$
C_{p}=4.187 \mathrm{~kJ} / \mathrm{kg} * \mathrm{k},{ }^{\circ} \mathrm{c}=\mathrm{k}-273.15 \text {, where } \mathrm{k}=\text { Kelvin, }{ }^{\circ} \mathrm{c}=\text { degree centigrade }
$$

\begin{tabular}{|c|c|c|c|c|c|c|c|c|}
\hline \multirow[b]{2}{*}{$\underset{\Xi}{\stackrel{\Xi}{\Xi}}$} & \multicolumn{4}{|c|}{ Black Coated Solar Cooker } & \multicolumn{4}{|c|}{ White Coated Solar Cooker } \\
\hline & 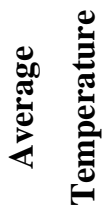 & 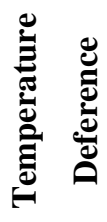 & 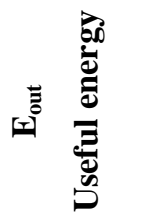 & 总 & 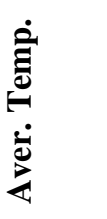 & D & 言 & 总 \\
\hline $4: 30$ & 35.94 & --- & --- & --- & 33.41 & --- & --- & --- \\
\hline $4: 35$ & 36.39 & 0.45 & 944.36 & 0.04 & 33.69 & 0.28 & 585.13 & 0.06 \\
\hline $4: 40$ & 39.24 & 2.85 & 5963.00 & 0.14 & 35.33 & 1.64 & 3443.14 & 0.25 \\
\hline $4: 45$ & 41.57 & 2.32 & 4865.92 & 0.09 & 37.36 & 2.03 & 4255.42 & 0.1 \\
\hline $4: 50$ & 44.67 & 3.11 & 6501.26 & 0.2 & 40.07 & 2.70 & 5660.87 & 0.23 \\
\hline $4: 55$ & 47.38 & 2.71 & 5682.39 & 0.11 & 42.14 & 2.08 & 4347.99 & 0.15 \\
\hline 5:00 & 50.08 & 2.69 & 5638.00 & 0.1 & 44.31 & 2.17 & 4536.47 & 0.12 \\
\hline $5: 05$ & 52.79 & 2.71 & 5677.45 & 0.11 & 46.78 & 2.46 & 5159.01 & 0.12 \\
\hline $5: 10$ & 55.03 & 2.24 & 4682.87 & 0.09 & 48.74 & 1.97 & 4119.02 & 0.1 \\
\hline $5: 15$ & 57.71 & 2.69 & 5624.48 & 0.11 & 51.15 & 2.41 & 5043.24 & 0.12 \\
\hline $5: 20$ & 59.93 & 2.22 & 4637.81 & 0.08 & 53.01 & 1.85 & 3883.34 & 0.1 \\
\hline $5: 25$ & 62.49 & 2.57 & 5370.37 & 0.11 & 55.44 & 2.44 & 5101.73 & 0.11 \\
\hline $5: 30$ & 65.25 & 2.76 & 5769.73 & 0.1 & 58.09 & 2.65 & 5539.95 & 0.11 \\
\hline $5: 35$ & 67.30 & 2.05 & 4295.51 & 0.08 & 60.03 & 1.94 & 4056.93 & 0.09 \\
\hline $5: 40$ & 69.12 & 1.82 & 3807.99 & 0.06 & 61.72 & 1.69 & 3544.86 & 0.06 \\
\hline $5: 45$ & 71.23 & 2.11 & 4409.37 & 0.07 & 63.84 & 2.12 & 4432.74 & 0.07 \\
\hline
\end{tabular}

Experiment result shows on Table 2 based on the recorded data calculated average temperature, useful energy and efficiency of both solar cookers for the 5 minutes (300 seconds) time interval.

Table 2 : White and Black Coated Solar Cooker Experiment Result 
International Journal of Advances in Scientific Research and Engineering (ijasre), Vol 5 (5), May-2019

\begin{tabular}{|c|c|c|c|c|c|c|c|c|}
\hline $5: 50$ & 73.51 & 2.29 & 4788.94 & 0.08 & 66.15 & 2.31 & 4842.79 & 0.08 \\
\hline $5: 55$ & 75.35 & 1.83 & 3840.53 & 0.18 & 68.06 & 1.91 & 3994.96 & 0.17 \\
\hline $6: 00$ & 75.63 & 0.28 & 591.43 & 0.06 & 68.62 & 0.56 & 1164.24 & 0.03 \\
\hline $6: 05$ & 75.09 & -0.54 & -1137.67 & -0.07 & 68.10 & -0.52 & -1079.05 & -0.08 \\
\hline $6: 10$ & 74.76 & -0.33 & -684.39 & -0.03 & 67.88 & -0.23 & -472.86 & -0.04 \\
\hline $6: 15$ & 74.86 & 0.10 & 215.25 & 0.02 & 68.09 & 0.21 & 440.37 & 0.01 \\
\hline $6: 20$ & 74.48 & -0.39 & -808.05 & -0.05 & 67.76 & -0.33 & -687.53 & -0.05 \\
\hline $6: 25$ & 73.74 & -0.74 & -1553.19 & -0.08 & 67.19 & -0.57 & -1185.65 & -0.11 \\
\hline $6: 30$ & 73.82 & 0.09 & 185.15 & 0.02 & 67.45 & 0.26 & 544.85 & 0.01 \\
\hline $6: 35$ & 73.30 & -0.52 & -1091.22 & -0.05 & 67.14 & -0.32 & -659.89 & -0.09 \\
\hline $6: 40$ & 72.41 & -0.89 & -1868.93 & -0.17 & 66.45 & -0.68 & -1430.80 & -0.22 \\
\hline $6: 45$ & 71.43 & -0.98 & -2060.88 & -0.2 & 65.75 & -0.71 & -1479.90 & -0.28 \\
\hline $6: 50$ & 70.22 & -1.21 & -2534.62 & -0.39 & 64.67 & -1.08 & -2258.76 & -0.44 \\
\hline
\end{tabular}

It is possible to say solar cooker (white inside coated) is better in efficiency than black inside coated solar cooker. These graph shown and represented variation about output energy of the black inside and white inside coated box solar cooker corresponds to time, the temperature difference respect to water temperature .shows the comparison of useful energy of the two box solar cookers.

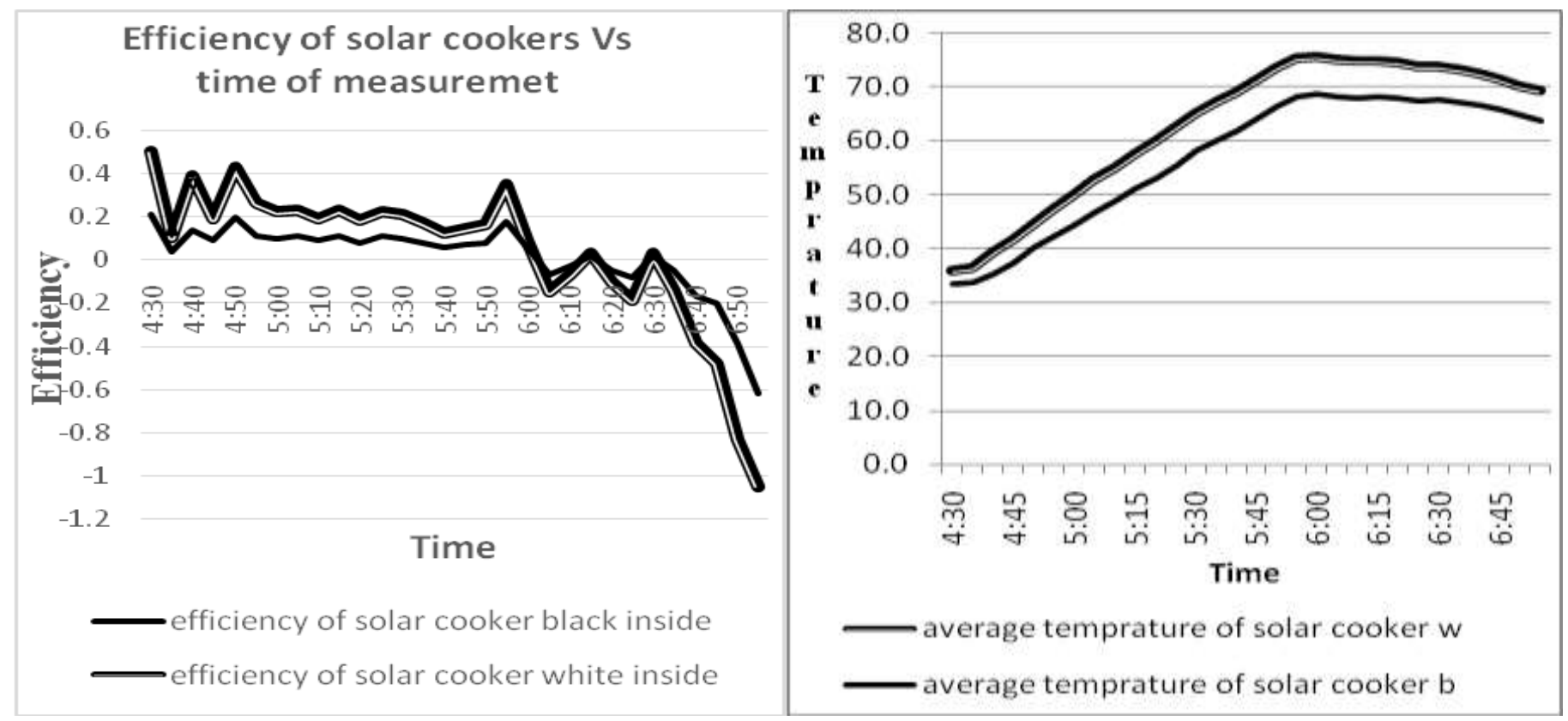

Figure 3: Efficiency Vs. Time

Figure 4: Temperature difference between solar cookers

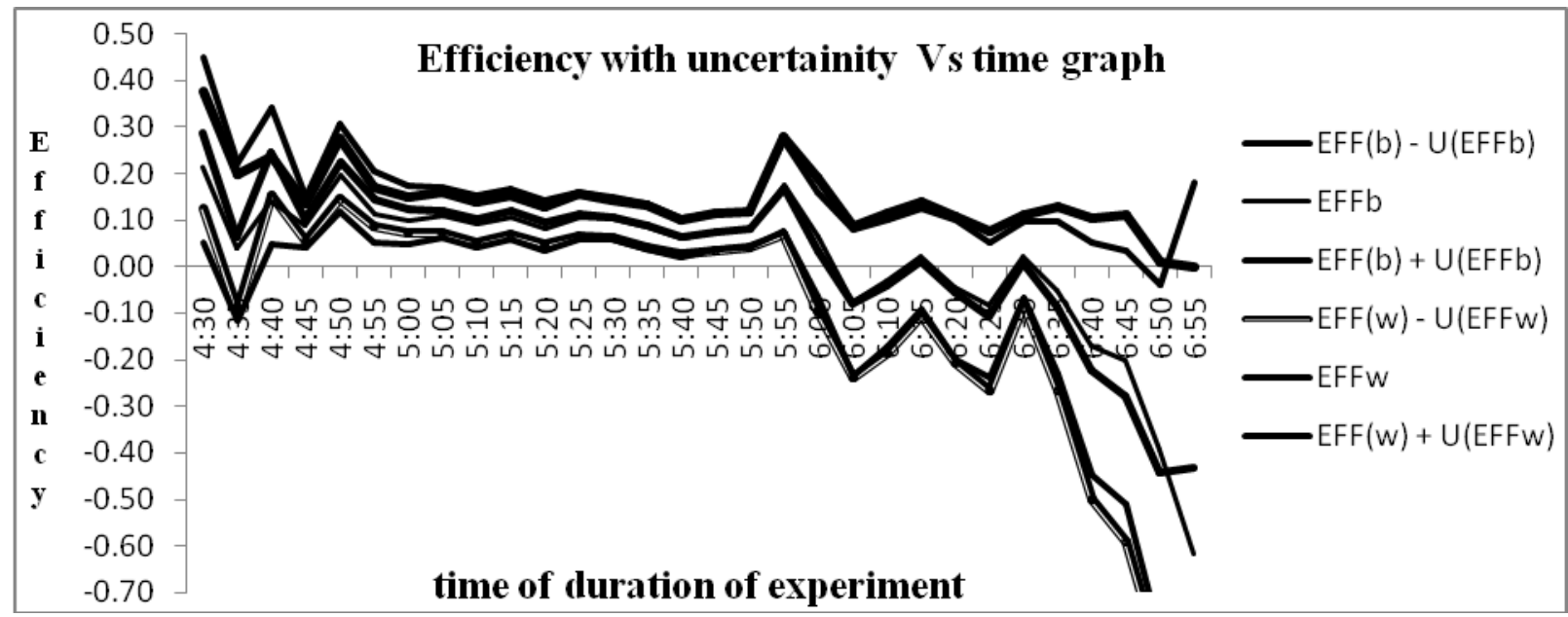

Figure 5: shows when possible efficiency ranges of both solar cookers drawn together 


\section{CONCLUSION}

Results from the testing showed that the temperature of the water reached maximum of $75.63^{\circ} \mathrm{C}$ for white coated solar box cooker and $68.62^{\circ} \mathrm{C}$ for black coated solar box at the same time 6:00pm. The maximum $\mathrm{E}_{\text {out }}$ Useful Energy recorded at 4:50pm on both the result $\mathrm{E}_{\text {out }}$ white coated $6501.26 \mathrm{~J}$ and $\mathrm{E}_{\text {out }}$ black coated 5660.87J. Looking the graph of efficiency Vs. time in Figure 4 ,temperature Vs. time graph in figure 5 and $\mathrm{E}_{\text {out }}$ Useful Energy Vs time figure 6 for both solar cookers it shows solar cooker w (white coated inside) is more efficient than solar cooker b (black coated inside). Looking the result and graph shows the black coated solar box absorb the input solar energy and do not reflect to the black pot as compare with white coated solar box, this bring the white coated solar box more efficient. The final conclude solar cooker w (white inside) is more efficient than the solar cooker b (black inside).

\section{REFERENCES}

1. Rachel Martin, Design of Solar Ovens for Use in the Developing World, Cornell Solar Oven Team Fall 2005 - spring 2006 , International Journal for Service Learning in Engineering, Vol. 2, No. 1, pp. 78-91, Fall 2006, ISSN 1555-9033.

2. Dinesh kumar.c.m, box type solar cooker, International journal of scientific research, Volume 3, Issue 11, November 2014, ISSN 2277-8179.

3. C Z M Kimambo, 2007, Development and performance testing of solar cookers, Journal of Energy in Southern Africa, Vol 18 NO 3, pp41 -51.

4. Ismail Isa Rikoto, Comparative Analysis on Solar Cooking Using Box Type Solar Cooker with Finned Cooking Pot, International Journal of Modern Engineering Research (IJMER), Vol.3, Issue.3, May-June. 2013 pp-1290-1294 ISSN: 22496645.

5. S. Paranthaman, Overcoming the Low Efficiency of Box Type Solar Cookers, Indian Journal of Science and Technology, Vol 8(S2), 82-84, January 2015, ISSN (Online) : 0974-5645

6. S. Periasamy, Modernised Solar Cooker, International Science Press, IJCTA, 9(2) 2016, pp. 619-624.

7. Ibrahim Ladan Mohammed, Design and Development of a Parabolic Dish Solar Thermal Cooker, International Journal of Engineering Research and Applications, Vol. 3, Issue 4, Jul-Aug 2013, pp.1179-1186, ISSN: 2248-9622 